\title{
Drought tolerance selection of GT1 rubber seedlings with the addition of polyethylene glycol (PEG) 6000
}

\author{
SYARIFAH AINI PASARIBU ${ }^{1}$, MOHAMMAD BASYUNII, ${ }^{2,}$, EDISON PURBA ${ }^{3}$, YAYA HASANAH ${ }^{3}$ \\ ${ }^{1}$ Doctoral Program of Agricultural Sciences, Faculty of Agriculture, Universitas Sumatera Utara. Jl. Dr. A Sofyan No. 3, Medan 20155, North Sumatra, \\ Indonesia \\ ${ }^{2}$ Department of Forestry, Faculty of Forestry, Universitas Sumatera Utara. Jl. Tri Dharma Ujung No. 1, Medan 20155, North Sumatra, Indonesia. \\ Tel.: +62-61-8213236/8222451, Fax.: +62-61-8211924, `email: m.basyuni@usu.ac.id \\ ${ }^{3}$ Department of Agrotechnology, Faculty of Agriculture, Universitas Sumatera Utara. Jl. Prof. A. Sofyan No. 3, Medan 20155, North Sumatra, Indonesia
}

Manuscript received: 18 November 2020. Revision accepted: 27 December 2020.

\begin{abstract}
Pasaribu SA, Basyuni M, Purba E, Hasanah Y. 2021. Drought tolerance selection of GT1 rubber seedlings with the addition of polyethylene glycol (PEG) 6000. Biodiversitas 22: 394-400. Tolerance of the rootstock of rubber to drought stress is not optimal. The root system can therefore be used as an indicator of drought tolerance to inhibit the growth of the plant. A good root system of rubber rootstocks is thought to help the plants acquire greater resistance to drought stress. Polyethylene glycol 6000 osmotic solution controls the water potential in the growing medium. This study aimed to analyze the effect of PEG 6000 osmotic solution $(0 \%$; $7.5 \%$; and $15 \%$ concentration) on rubber seedlings leading to the development of morphological characters and sensitivity index. GT1 (Gondang Tapen 1) rubber seeds to be used as planting material were collected from the seed source garden of PT Socfin Indonesia. The study was carried out from January to February 2019, using a non-factorial randomized block design. The morphological characters observed were tapped root length, shoot height, the increased rate of taproot length, shoot height increase rate, ratio of taproot length, and shoot height. Data were analyzed using analysis of variance, discriminant, and drought stress sensitivity index. The results showed that the addition of PEG 6000 in planting media in vitro significantly influenced the character of the rate of increase of taproot length. The sensitivity index of taproot increase rate and the ratio of taproot length and shoot height was moderate at $7.5 \%$ level. By contrast, the addition of PEG 6000 in planting media in vitro did not significantly impact it. The present study suggested that the rate of increase of taproot length was a distinguishing character showing the initial tolerance level of the GT1 seedlings to drought.
\end{abstract}

Keywords: Drought, polyethylene glycol 6000, rubber seedlings, selection

\section{INTRODUCTION}

Rootstock in the multiplication of rubber seedlings is still used nowadays, with other approaches, still at the development research stage. Drought-tolerant rootstock is very helpful for rubber growth and is essential for accurate detection of drought stress. Early detection of drought stress can be carried out by osmotic materials, such as polyethylene glycol (PEG) 6000. PEG 6000 is a flexible polymer that can dissolve in water and methanol, has a low toxic content, and can also make the media dry. PEG 6000 can be used for drought stress simulations which can duplicate water potential levels (Verlues et al. 2006). Simulated drought stress can be imposed on hydroponics systems by two methods. First, the nutrient solution can be supplemented by PEG in order to reduce the osmotic potential of the medium, which is subject to many conditions and precautions. Secondly, the nutrient solution level can be allowed to be drawn down by transpiration or actively reducing its level, so that only the lower part of the root will be immersed in the solution. Under sufficient evaporative demand, such plants will not be able to absorb enough water and stress symptoms will develop (https://plantstress.com/drought).

The solution of PEG 6000 at a concentration $5-20 \%$ for in vitro has been reported to inhibit the osmotic potential with soil conditions in the field capacity of some plants, such as wheat (Öztürk et al. 2016; Faisal et al. 2019), barley (Mapikasari et al. 2017; Hellal et al. 2018), rice (Nazirah et al. 2015; Abiri et al. 2016; Widyastuti et al. 2016; Akbar et al. 2018; Purbajanti et al. 2019), soybean (Savitri 2010; Zuyasna et al. 2016), eggplant (Sinaga et al. 2015), plantain (Irawan et al. 2015). A few studies report the application of PEG 6000 on the rubber plant.

The early vegetative phase of plants observed with drought stress showed that the length of the roots is long, with many branches and large volumes (Sobrado 2007). The rootstock root system can be used as an indicator to observe the ability of adaptation to the environment. The effects of drought stress include obstruction of plant growth, such that the growth rate of the girth and thickness is late, with the time to open tapping taking a long time (> six years). The development of drought-tolerant rootstocks is believed to prepare a strong root system under stress conditions (Daslin et al. 2009).

In vitro selection for resistance to drought stress has comparative advantages, including shorter selection, lack of need for large space, and easy control. Types of rootstock seeds that are widely available in the field include GT1 (Gondang Tapen 1) seeds. The initial characters were needed to understand the effect of PEG 6000 osmotic solution on the morphological characters and sensitivity index. Therefore, the present study aimed to investigate the effect of PEG 6000 osmotic solution $(0 \%$; $7.5 \%$; and $15 \%$ concentration) on rubber seedlings to the 
development of morphological characters (taproot length, shoot height, taproot length increase rate, shoot height increase rate, a ratio of taproot length and shoot height) and sensitivity index.

\section{MATERIALS AND METHODS}

\section{Study area}

The research area is the greenhouse of Experimental Garden Sungei Putih Research Center, Rubber Research Institute, Medan, North Sumatra, Indonesia, at an altitude of $80 \mathrm{~m}$ above sea level.

\section{Plant materials}

Ten years' GT1 seeds were used as plant materials, collected from PT. Socfin Indonesia seed source garden. The GT1 seed before germination is depicted in Figure 2.

\section{Chemicals}

Ingredients for planting media included MS (Murashige and Skoog 1962), NaOH 1N, PEG 6000, chloroform, methanol, aquadest, and ethanol.

\section{Procedures}

The seeds were germinated in sand media for 14 days. Planting media was $1 / 4$ MS (1963) liquid. The $\mathrm{pH}$ of the planting medium was measured by adding $\mathrm{NaOH} 1 \mathrm{~N}$ to set the media $\mathrm{pH}$ to 5.8. PEG 6000 was added to each treatment with concentrations of $0 \%, 7.5 \%$, and $15 \%$. The planting medium was made aseptic. Initially, the media was made in the laboratory, filled in a greenhouse, put into an aquarium and equipped with an aerator. The experimental unit consisted of three treatments, comprising the differences in the concentration of PEG $6000(0 \%, 7.5 \%$, and 15\%). Each treatment was repeated thrice and each replication consisted of 15 plants. Initially, the seeds were germinated in the sand medium for \pm 14 days and thereafter, the germinated seeds were put into liquid planting medium $1 / 4 \mathrm{MS}+$ several concentrations of PEG 6000 and observed for a week (Figure 4). The characters observed were taproot length $(\mathrm{cm})$, shoot height $(\mathrm{cm})$, taproot length and shoot height ratio, taproot length increase rate $(\mathrm{cm})$, and shoot height increase rate $(\mathrm{cm})$. The length of the taproot was measured using a fabric meter, from the neck root to the tip of the taproot for six days. The shoot height was measured using a fabric meter from the growing point to the root neck for six days. The ratio of taproot length and shoots was measured by comparing the value of the length of the taproot and shoot height.

\section{Data analysis}

The analysis of data was performed with a variety of analysis, according to the experimental design used. Drought stress sensitivity index (SSI) (Widyastuti et al. 2016)) was calculated by the formula:

$$
\mathrm{SSI}=(1-\mathrm{Yc} / \mathrm{Yo}) /(1-\mathrm{XC} / \mathrm{Xo})
$$

Where: Yc: an average of certain genotypes under drought stress conditions, Yo: an average of genotypes under optimum conditions, Xc: an average of all genotypes under drought stress conditions, and Xo: an average of all genotypes under optimum conditions.

The criterion for determining the tolerance level to drought stress was this: if the SSI value is 0.5 , then the genotype is tolerant if $0.5<\mathrm{SSI} \leq 1.0$, the genotype is moderate, and if SSI> 1.0 then the genotype is sensitive (Widyastuti et al. 2016). SSI value was used as the basis for determining the classification of the tolerance characteristics of the drought seeds tested. The software used for variance analysis and discriminant analysis was Microsoft Excel 2010 and Minitab-16. The study was arranged using a non-factorial randomized block design, with some concentrations of PEG $6000(0 \%, 7.5 \%$, and $15 \%)$, replicated thrice. When testing the variance obtained, significantly different treatments were performed with the Tukey test.

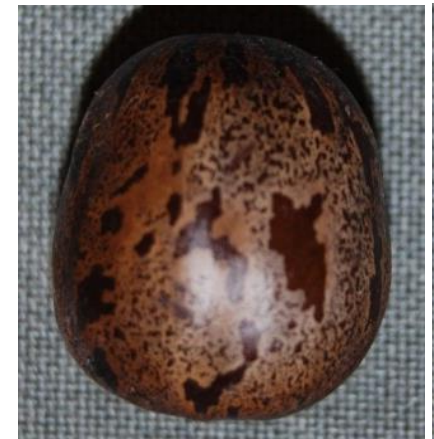

A

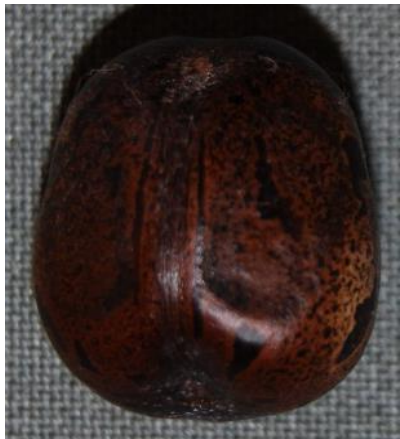

B
Figure 2. Performance GT1 seed before germination. A. Dorsal, B. Ventral
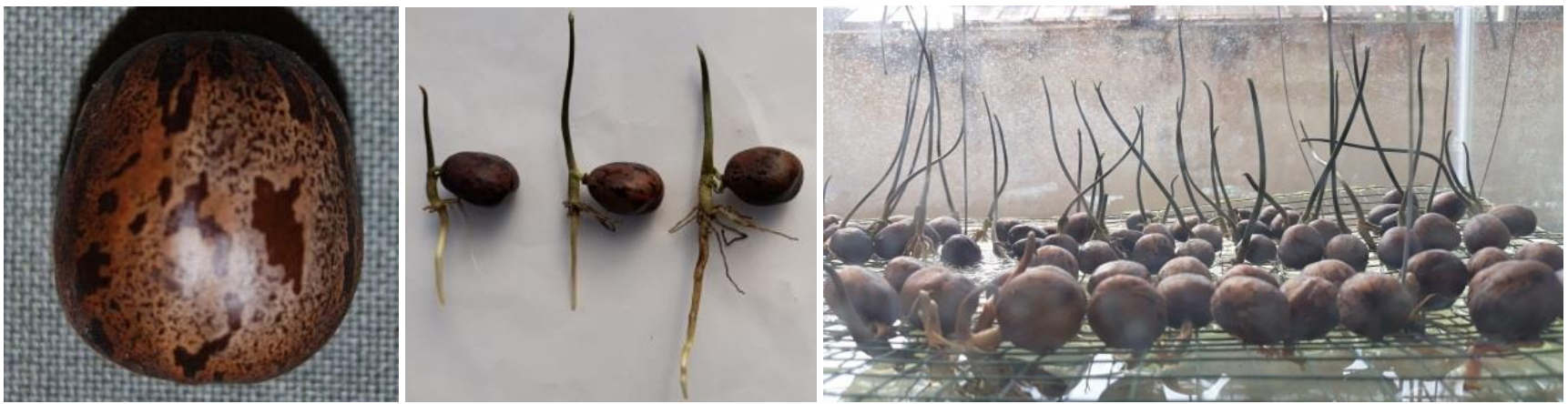

Figure 4. A. Seed of GT1 rubber clone; B. Rubber seedling after 14 days is planted in sand medium; C. Rubber seedling is planted in liquid medium of $1 / 4 \mathrm{MS}+$ PEG $6000(0 \%, 7,5 \%, 15 \%)$ 


\section{RESULTS AND DISCUSSION}

\section{Taproot length and shoot height}

The average taproot length of each treatment was 6.96 $\mathrm{cm}(0 \%), 3.88 \mathrm{~cm}(7.5 \%)$ and $2.03 \mathrm{~cm}(15 \%)$. The observations showed that with regard to the growth of GT1 seedlings, the growth of fresh-looking taproots was indicated by the white color that was different from the $7.5 \%$ and $15 \%$ treatments. The tip of the taproot looked black and wrinkled (Figure 5) when PEG 6000 was not added to the planting media (0\%) and when PEG 6000 (7.5\%) was added to the medium. This was illustrated by the coefficient variation of $19.14 \%$ and $11.57 \%$. When $15 \%$ of PEG 6000 was added to the medium, the root growth looked very diverse reflected in the coefficient of variation which was equal to $23.99 \%$. The detail of the taproot length pattern of GT1 seedlings is displayed in Figure 5.

Besides the taproot length character, another character, shoot height, was affected by the addition of PEG 6000 . The average shoot height of GT1 seedlings after planting on $1 / 4 \mathrm{MS}$ medium with PEG 6000 was $10.82 \mathrm{~cm}(0 \%), 9.05$ $\mathrm{cm}(7.5 \%)$, and $6.04 \mathrm{~cm}(15 \%)$, respectively. The shoot height in this treatment looked varied, as illustrated by the coefficient variation either without the addition of PEG 6000 or after its addition. The growth pattern of shoot height of GT1 seedlings of some concentrations of PEG 6000 is depicted in Figure 5.

The same pattern between taproot length and shoot height is shown in Figures 6 and 7. The analysis variance of shoot height showed no significant effect between the PEG treatments added to the planting media, while after the observation time of six days, significant differences were reflected after analysis of variance. A perceptible difference was observed between the first three days and the next three days.

\section{Taproot length and shoot height increase rate}

The taproot length increase rate of GT1 seedlings observed from the first day to the sixth reflected the same pattern. The growth rate seemed to be decreasing, especially for the treatment with the addition of PEG 6000 with medium concentration $(7.5 \%$ and $15 \%)$. The average of taproot length increase rate was $1.05 \mathrm{~cm}(0 \%), 0.43 \mathrm{~cm}$ $(7.5 \%)$ and $0.37 \mathrm{~cm}(15 \%)$, respectively. The diversity of the rate of increase in taproot growth was also quite diverse among the treatments described by the coefficient of variation that was $18.67 \%(0 \%), 28.63 \%(7.5 \%)$, and $43.63 \%(15 \%)$. The pattern of the taproot length increase rate is depicted in Figure 6. The analysis variance showed significant differences between treatments, seen mainly between treatments with and without the addition of PEG 6000. There was a real effect due to the addition of PEG 6000 , with the increase in taproot length inhibited even visually, with the roots of the plant looking increasingly blackened and withered.

A similar pattern was observed in the rate increase of shoot height. The same pattern did not reflect the same results, as the rate of shoot height increased. After an analysis of variance, the addition of PEG 6000 treatment to the planting median of the GT1 seedlings showed nonsignificant differences between treatments. The difference was seen on the day of observation was the difference between the observations of the second day and the following day. The average rate increase of shoot height from the first day to the sixth was $1.87 \mathrm{~cm}(0 \%), 1.50 \mathrm{~cm}$ $(7.5 \%)$, and $1.01 \mathrm{~cm}(15 \%)$. High diversity was also seen in the rate increase of shoot height, as illustrated by the coefficient variation for each treatment, namely $46.38 \%$ (0\%), $48.77 \%(7.5 \%)$, and $38.10 \%(15 \%)$. The pattern of rate of increase of shoot height is displayed in Figure 8.

\section{The ratio of taproot length and shoot height}

The ratio of taproot length and shoot height without PEG 6000 showed an elevated pattern, unlike the pattern with the addition of PEG 6000 , especially for the $15 \%$ concentration. A fairly sloping pattern was very evident. The average ratio of taproot length and shoot height of each treatment was $29.87 \%(0 \%), 64.33 \%(7.5 \%)$, and $45.01 \%$ (15\%). The pattern ratio of taproot length and shoot height is shown in Figure 9. Analysis variance of the character showed no significant difference between treatments. This was thought to be due to the smaller increase in plant parts that support the growth and development of plants due to the influence of PEG 6000.

\section{Sensitivity index}

The sensitivity index value is used to determine the tolerance value of a plant to sub-optimal environmental conditions. This value was obtained from the comparison of the average character recorded genotype, compared to the average of the characters from all the treatments used, but this value was still used as an estimator to classify the GT1 seedlings into the tolerant group. The sensitivity index values of the five characters observed are displayed in Table 1 . The sensitivity index value in $7.5 \%$ level showed two characters classified as moderate, namely, tap root increase rate (0.7) and taproot length and shoot height ratio $(0.8)$, while the other characters (taproot length, shoot height, shoot increase rate) are classified as susceptible. The sensitivity index value at the $15 \%$ level concentration indicates that all characters observed are classified as susceptible to the PEG 6000 treatment applied.

\section{The visualization of root and shoot of GT1 after PEG 6000 treatments}

The visual observations of the addition of PEG 6000 on planting media with three different concentrations were significantly different. At $0 \%$ concentration, the GT1 seedlings could grow and develop well, as indicated by root and shoot looking fresh. At 7.5\% concentration, the growth of seedlings was disrupted, which is seen in the taproots starting to wilt and turn black; however, the shoot still looked fresh. At $15 \%$ concentration, the growth of seedlings was completely disrupted by increasingly damaged taproots (withering and blackening) as well as buds that also look withered. The visual appearance of the rubber seedlings is depicted in Figure 10. 
Table 1. Sensitivity index values of GT1 seedlings to taproot length, shoot height, taproot increase rate, shoot height increase, and ratio of taproot length and shoot height on $1 / 4 \mathrm{MS}$ medium to which were added various concentrations of PEG 6000

\begin{tabular}{lcc}
\hline \multirow{2}{*}{ Observed character } & \multicolumn{2}{c}{ Sensitivity index } \\
\cline { 2 - 3 } & $\mathbf{7 . 5 \%}$ & $\mathbf{1 5 \%}$ \\
\hline Taproot length & 1.2 & 1.3 \\
Shoot height & 1.1 & 1.2 \\
Taproot increase rate & 0.7 & 1.2 \\
Shoot height increase rate & 2.0 & 2.9 \\
Taproot length and shoot height ratio & 0.8 & 1.3
\end{tabular}

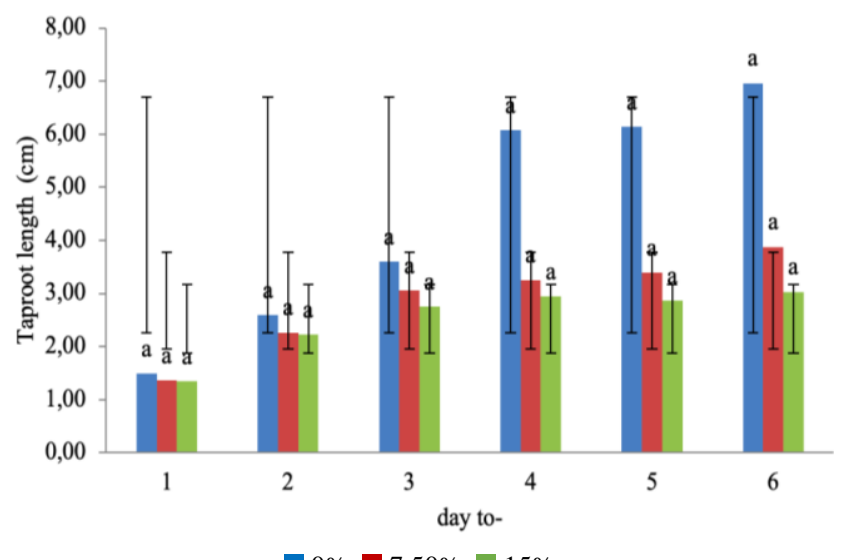

Figure 5. Taproot length of GT1 seedling for six days on $1 / 4 \mathrm{MS}$ medium with various added concentrations of PEG 6000. Data are represented as mean $\pm \mathrm{SD}$. Means with the same letter are not significantly different for each other $(\mathrm{P}<0.05)$ using Tukey test

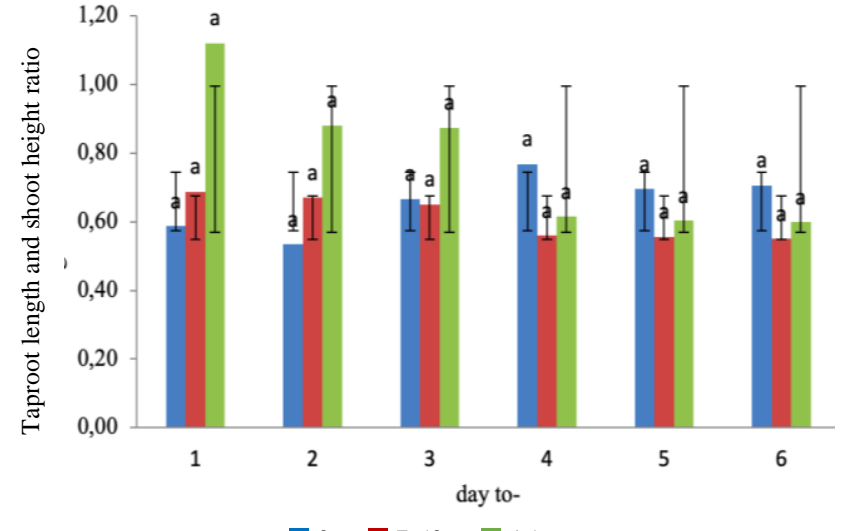

$0 \%, \square 7.50 \%, \square 15 \%$

Figure 7. The increased rate of taproot length of GT1 seedlings in $1 / 4 \mathrm{MS}$ medium to which were added various concentrations of PEG 6000. Data are represented as mean \pm SD. Means with the same letter are not significantly different for each other $(\mathrm{P}<0.05)$ using Tukey test

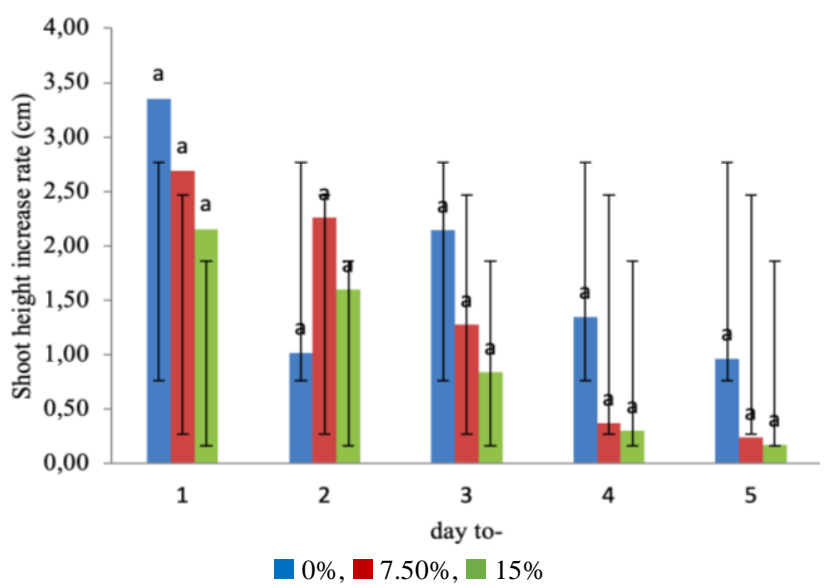

Figure 8. The increased rate of shoot height of GT1 seedlings on $1 / 4$ MS medium to which were added various concentrations of PEG 6000. Data are represented as mean \pm SD. Means with the same letter are not significantly different for each other $(\mathrm{P}<0.05)$ using Tukey test

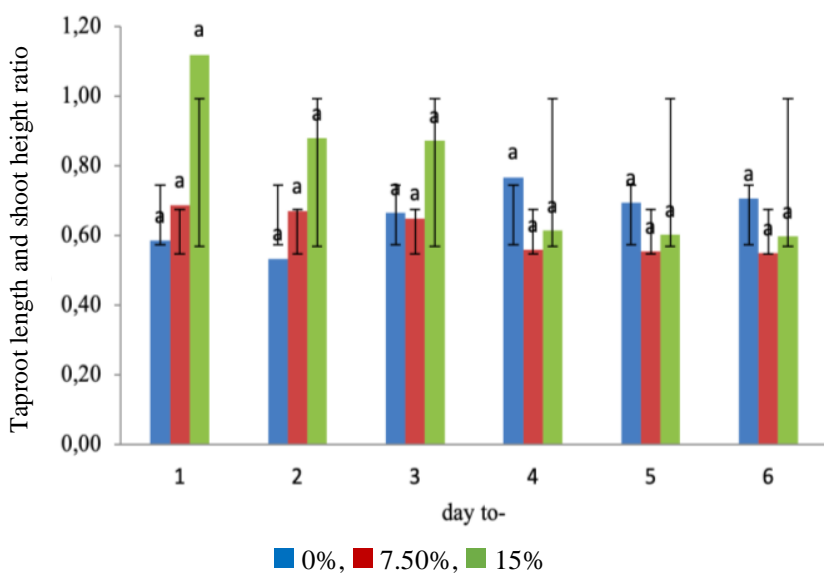

Figure 9. The ratio of taproot length and shoot height of GT1 seedlings on $1 / 4$ MS medium to which were added various concentrations of PEG 6000. Data are represented as mean \pm SD. Means with the same letter are not significantly different for each other $(\mathrm{P}<0.05)$ using Tukey test 


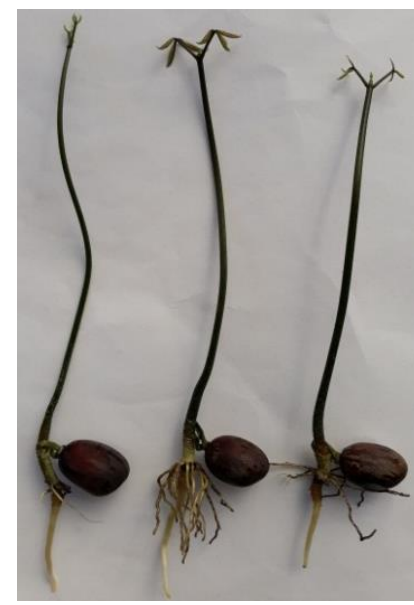

A

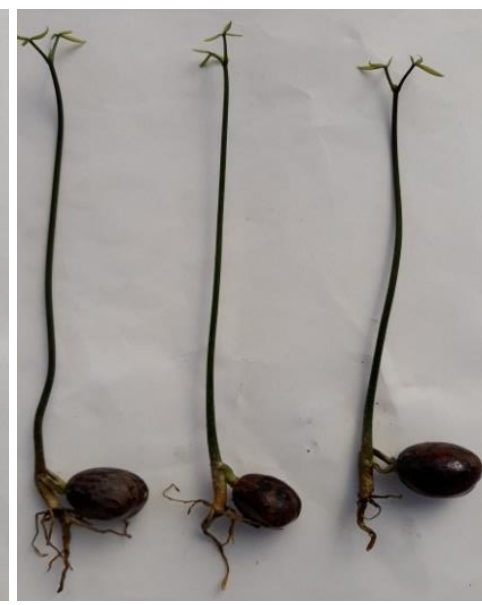

B

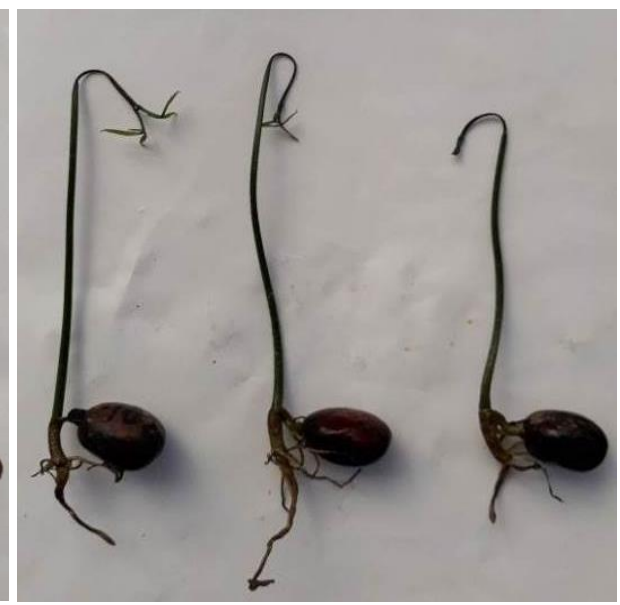

C

Figure 10. The visualization of roots and shoots of GT1 seedling on $1 / 4 \mathrm{MS}$ medium, to which were added various concentrations of PEG 6000 on $0 \%$ (A), $7.5 \%$ (B), and $15 \%$ (C)

\section{Discussion}

This was a simulation by polyethylene glycol (PEG) of water stress-induced on plants (Meher et al. 2018). Duman (2006) showed that water stress decreases the percentage of radicle and plumule length in the germination of seed. Crop germination and seedling growth are very important for the early establishment of plants under water stress conditions (Islam et al. 2018). Growth reduction is a significant parameter for evaluating the tolerance to water stress. This circumstance occurred because growth was directly related to mass, and the possible damage to mass when a plant is water-stressed. It is a basic parameter when differentiating tolerant genotypes too (Vanhove et al. 2012).

The part of the plant that absorbs water and nutrients is the root. Factors that affect the amount of water absorbed by plants are the water content in the soil, water stored in the soil, and the ability of plant roots to absorb water. Roots in plants that are water-deficient will increase the extent and depth of the root system to absorb water.

Analysis variance of taproot length showed a difference between the three treatments, indicating that PEG 6000 had affected the taproot length in each treatment. Generally, as seen from the average and the coefficient of variation, the growth of taproots began to be stunted, with growth of taproot length decreasing with the treatment of PEG 6000 with concentrations of $7.5 \%$ and $15 \%$. Plants with a good tolerance level to water stress showed a relatively small percentage of loss of root length and shoot length (Nazirah et al. 2016).

The seedling height of rice genotypes decreased due to water stress level, in response to five levels of water stress caused by PEG-6000 @ 0, 5, 10, 15, and 20\%. Increased water tension, in all genotypes, lowered germination from $95.8 \%$ in control to $6.6 \%$ in the top-level (20\% PEG) (Islam et al. 2018). Water stress weakens seed germination (Swain et al. 2014) and the height of the seedling (Sokoto and Muhammad 2014). The higher concentration of PEG 6000 lowers growth value, emergence value, germination energy, and the relative germination value on all rice cultivars (Purbajanti et al. 2019). The length of the main root in the first three youngest roots related to phytomers (Pr1-Pr3) was increased in Binadhan-11 and reduced in Binadhan-7, as long as BRRI 71 was under 5\% PEG treatment, compared to control. This result concluded that the length of the new root Binadhan-11 could have increased due to environmental stress. The lateral length of the L-type root was also increased by 2.03 fold in Binadhan-11 under PEG 5\%, compared to energy. The density and length of the root hairs increased substantially at first-order lateral roots in Binadhan-11 and slightly more than PEG 5\% compared to control, which mainly has a role in the root area (Hannan et al. 2020).

The results of the analysis of variance indicated that the germination and seedling growth parameters used in this experiment can aid in the discrimination between tolerant and susceptible cultivars of lettuce, when evaluated for water stress with PEG 6000 (Liu et al. 2017).

Based on the sensitivity index values, the observed characters were classified as sensitive groups (SSI> 1). SSI values indicated that the genotypes tested under suboptimum conditions did not show a large decrease so that it could be said that the genotype was not tolerant (Akbar et al. 2018). The level of sensitivity of rice to water stress varies with terms, space, severity, and growth stadia of the rice variety (Sokoto and Muhammad 2014). Based on the water stress sensitivity index (SSI) on the variable germination percentage, seminal root length, shoot length, sprout length, seminal root dry weight, dry shoot weights, and seed vigor, the treatment PEG 6000 concentration of $25 \%$ shows diversity tolerance of rice genotypes to drought stress (Widyastuti et al. 2016). The seedling vigor index is an appropriate selection criterion for drought tolerance, as it allows the classification of genotypes as tolerant, moderately tolerant, moderately susceptible, and susceptible (Koskosidis et al. 2020). 
Drought avoidance and drought tolerance are two mechanisms by which plants adapt under water stress. As these mechanisms are difficult to evaluate separately in field experiments using hydroponic culture, we studied the genetic control of drought tolerance without the effect of drought avoidance (Kato et al. 2008).

Research related to the use of PEG 6000 to simulate drought tolerance on rubber plant rootstock is quite limited. PEG $6000(15 \%, 25 \%, 35 \%)$ was used to assess the resistance of RRIM 600 clones to drought stress by soaking the seeds for 7 days in the solution. The assessment was performed on the physiological characters (superoxide dismutase, catalase, soluble sugar, proline, hydrogen peroxide, and superoxide free radical (Xianhai et al. 2010). The results of this study are expected to be used as an initial assessment for rootstock to be used during budding, especially if the rubber plantation is to be opened in real areas that are classified as dry. Similar research can continue to evaluate the recommended rootstock seeds other than the GT 1 clone, namely PB 260, RRIC 100 and AVROS 2037.

PEG 6000 can be used as a stimulant in rubber plants (Andriyanto and Darojat, 2016; Rahayu et al. 2017), for preserving the vigor and viability of rubber seeds during storage (Lubis et al. 2016; Charloq et al. 2017), coextraction of DNA and RNA from rubber plant (Zewei An et al. 2012), surfactant ingredients (Ismayana et al. 2017), Mechanical wounding (Tian et al. 2015).

PEG 6000 is used for simulations of drought stress carried out on perennial and annual crops. It is hence hoped that these things can be used as a reference in developing a method of testing rubber planting materials, so that they are tolerant of drought stress during the germination stage.

In this study, there was a negative effect on the visualization of roots and shoots of germinated rubber. Initially, the root tip began to look black, wrinkled, and finally burned. When the roots are damaged, the shoots begin to wither and eventually burn, turning black. The higher the PEG 6000 concentration applied to the planting medium, the greater and faster is the process of plant tissue destruction. Another factor that is also related to visual character is index sensitivity. Polyethylene glycol-induced drought had a generally negative effect on seedling morphological characters indicated by plumule and radicle length, number of adventitious roots as well as seedling biomass, and water content. The values of the sensitivity index trait implied that germination parameters were generally affected by drought more intensively than membrane characteristics and finally came the antioxidant enzymes with the least degree of suppression when applying stress (Mickky and Aldesuquy, 2017). Prolonged drought stress dramatically decreased growth and photosynthetic capacity of three alfalfa varieties, after a 12day period of drought stress simulated by $-1.2 \mathrm{MPa}$ polyethylene glycol (PEG-6000) (Zhang et al. 2019).

The germination velocity, seed height, wet weight, dry weight, and sensitivity index were seen to be lower in sunflower plants with the addition of PEG 6000 to the planting medium during the drought stress simulation (Razzaq et al. 2017). PEG 6000 added to the planting medium as much as $20 \%$ causes the potential of media water to be lower than the potential of cell water, so that the macronutrient compounds in the media cannot move into the cell by osmosis and consequently the soybean shoots cannot grow and develop (Zuyasna et al. 2016). PEG 6000 decreased seed germination when water stress occurred and also delayed cassia germination (Safarnejad,2008). PEG 6000 added to spinach media (20\% and $30 \%$ ) significantly decreased the number of leaves, wet weight and dry weight (Annisa et al. 2020). The viability and vigor are different between each cultivar observed during water stress levels, after cotton treatment of potentials water with PEG 6000 (Carlos et al. 2011). Lower growth was seen in maize roots due to $\mathrm{Cu}(\geq 300 \mu \mathrm{M})$ and in shoots due to PEG 6000 (10\%) (Mamta and Meeta, 2019). The germination percentage of tomatoes decreased with increasing PEG 6000 treatments $(-0,5 \mathrm{Mpa})$ (Marilyn et al. 2018). Increase in PEG concentrations caused a decrease in germination, with an increase in the ratio of roots to shoots of Gossypium (Megha et al. 2017).

In conclusion, the rate of increase of taproot length is a distinguishing characteristic that can be applied to assess the initial tolerance level of the GT1 seedlings to drought. Index sensitivity value shows that the characters of taproot increase rate and the ratio of taproot length and shoot height are moderate at a $7.5 \%$ level.

\section{ACKNOWLEDGEMENTS}

This study was supported by the Penelitian Disertasi Doktor project No. 11/AMD/E1/KP.PTNB/2020, of the Directorate General of Research and Community Service, the Ministry of Research and Technology/National Agency for Research and Innovation of the Republic of Indonesia.

\section{REFERENCES}

Abiri R, Shaharuddin NA, Maziah M. 2016. Quantitative assessment of indica rice germination to hydropriming, hormonal priming, and polyethylene glycol priming. J Chilean Agric Res 76 (4): 392-400.

Andriyanto M, Darojat MR. 2016. Potential of polyethylene glycol (PEG) as latex stimulant in rubber plants (Hevea brasiliensis Muel. Arg). Agrovigor 9 (1): 73-81.

Annisa NF, Tundjung TH, Zulkifli, Martha LL. 2020. The effect of PEG (Polyethylene Glycol) 6000 on water spinach (Ipomoea reptans L.) growth. J Exp Biol Biodiv 7 (1). DOI: 10.23960\%2Fj_bekh.v7i1.2451

Akbar MR, Purwoko BS, Dewi IS, Suwarno WB. 2018. Determination the index of drought tolerance selection in the rainfed lowland paddy fields in the germination phase. J Agron Indonesia 46 (2): 133-139.

Charloq, Yazid A, Gustiansyah PP. 2017. Viability of shelled rubber (Hevea brasiliensis Muell. arg.) seed treated with PEG 6000 at different. J Agronom 16 (2): 83-86.

Carlos HSGM, R de Lucena A Bruno, Pedro DF, Walter EP, Leonardo HG. de Morais L, Marleide M de Andrade L, Márcia SV. 2011. Germination of cotton cultivar seeds under water stress induced by polyethylene glycol-6000. Sci Agric (Piracicaba, Braz.) 68 (2): 131138.

Daslin A, Woelan S, Lasminingsih M, Hadi H. 2009. Progress in breeding and selection of rubber plants (Hevea brasiliensis Muell. Arg.) in Indonesia. Proceedings National Workshop on Rubber Plant Breeding. Batam, August 4-6, 2009. Rubber Research Institute, Medan, Indonesia.

Duman I. 2006. Effects of seed priming with PEG or K3PO4 on germination and seedling growth in lettuce. J Biol Sci 11: 923-928. 
Faisal S, Mutjaba SM, Asma, Mahboob W. 2019. Polyethylene glycol mediated osmotic stress impacts on growth and biochemical aspect of wheat (Triticum aestivum L.). J Crop Sci Biotech 22 (3): 213-223.

Hannan A, Hassan L, Hoque MN, Ul Arif MT, Robin AHK. 2020 Increasing new root length reflects survival mechanism of rice (Oryza sativa L.) genotypes under PEG-induced osmotic stress. Plant Breed Biotech 8 (1): 46-57.

Hellal FA, El Shabrawi HM, Abd El-Hady M, Khatab IA, El-Sayed SAA, Abdelly C. 2018. Influence of PEG induced drought stress on molecular and biochemical constituents and seedling growth of Egyptian barley cultivars. Gen Eng Biotechnol 16: 203-212.

Irawan A, Nurcahyani E, Zulkifli. 2015. The chlorophyll content of plantain (Musa paradisiaca) leaves from in vitro selection of drought stress. Proc Natl Polytech Food Self-sufficiency. Lampung April $29^{\text {th }}$ 2015, 74-79.

Islam MM, Kayesh E, Zaman E, Urmi TA, Haque MH. 2018. Evaluation of rice (Oryza sativa L.) genotypes for drought tolerance at germination and early seedling stage. The Agriculturists 16 (1): 44 54.

Ismayana A, Maddu A, Saillah I, Mafquh E, Indrasti NS. 2017. Synthesis of nanosilica from boiler ash of sugar cane industry with ultrasonication method and addition of surfactant. Jurnal Teknologi Industri Pertanian 27 (2): 228-234. [Indonesian]

Liu CJ, Duan YL, Wang L, Han YY, Hao JH, Fan SX. 2017. Comprehensive evaluation of drought stress tolerance of twenty species of lettuce at the seed germination stage during PEG 6000 stress. Intl Conf Biol Sci Technol. DOI: 10.2991/bst-17.2018.46

Lubis Z, Siregar TH, Damanik SB, Yazid A, Husni M. 2016. Physiology changes of shelled rubber (Hevea brasilliensis Muell. Arg.) seed after 16 days storage with PEG $600030 \%$ coating to induce secondary dormancy. J Agron 15 (1): 11-18.

Kato Y, Hirotsu S, Nemoto K, Yamagishi J. 2008. Identification of QTL controlling rice drought tolerance at seedling stage in hydroponic culture. Euphytica 160: 423-430. DOI: 10.1007/s10681-007-9605-1

Koskosidis A, Ebrahim K, Mavromatis A, Pavli1 O, Vlachostergios DN 2020. Effect of PEG-induced drought stress on germination of ten chickpea (Cicer arietinum L.) genotypes. Notulae Botanicae Hort Agrobotanici Cluj-Napoca 48 (1): 294-304. DOI: 10.15835/nbha48111799.

Mamta H, Meeta J. 2019. Early seedling growth affected by $\mathrm{CuSO}_{4}$ and its combination with PEG 6000 in maize. Plant Sci Today 6 (2): 160169.

Mapikasari S, Adisyahputra, Indrayanti R. 2017. The germination of four barley accessions (Setaria italica) in conditions of artificial drought stress. J Bioma 1: 43-50.

Megha BR, Mummigatti UV, Chimmad VP, Aladakatti YR. 2017. Evaluation of hirsutum cotton genotypes for water stress using PEG 6000 by slanting glass plate technique. Intl J Pure Appl Biosci 5 (2): 740-750.

Mickky BM, Aldesuquy HS. 2017. Impact of osmotic stress on seedling growth observations, membrane characteristics and antioxidan defense system of different wheat genotypes. Egypt J Basic Appl Sci 4: 47-54. DOI: 10.1016/j.ejbas.2016.10.001

Murashige T, Skoog F. 1962. A revised medium for rapid growth and bioassay with tobacco tissue cultures. Physiol Plant 15: 473-497.

Nazirah L, Purba E, Hanum C, Rauf A. 2015. Evaluation of tolerance of upland rice to drought stress by using PEG (Polyethylene glycol). Lentera 15 (16): 61-68.

Öztürk Ali, Bilgi Taşkesenligil, Kamil Haliloğlu, Murat Aydin, Özcan Çağlar. 2016. Evaluation of bread wheat genotypes for early drough resistance via germination under osmotic stress, cell membrane damage, and paraquat tolerance. Turk J Agric For 40: 146-159

Purbajanti ED, Kusmiyati F, Fuskhah E, Rosyida R, Adinurani PG, Vincevica-Gaile Z. 2019. Selection for drought-resistant rice (Oryza sativa) using polyethylene glycol. IOP Conf Ser: Earth Environ Sci 293: 012014. DOI:10.1088/1755-1315/293/1/012014.

Rahayu MR, Nurhayati, Tistama R, Asbur Y. 2017. The role of PEGbased stimulants application on the production and physiology character of clone PB 260. Intl J Sci: Basic Appl Res 36 (6): 165-173.

Razzaq H, Tahir MHN, Sadaqat HA, Sadia B. 2017. Screening of sunflower (Helianthus annus L.) accessions under drought stress conditions, an experimental assay. J Soil Sci Plant Nutr 17 (3): 662 671.

Safarnejad A. 2008. Morphological and biochemical response to osmotic stress in Alfalfa (Medicago sativa L). Pak J Bot 40 (2): 735-746.

Savitri ES. 2010. In vitro testing of several drought-tolerant varieties of soybean (Glycine max) using polyethylene glycol (PEG) 6000 on solid and liquid media. El-Hayah 1 (2): 9-13.

Sinaga E, Rahayu MS, Maharijaya A. 2015. Seleksi toleransi kekeringan in vitro terhadap enam belas aksesi tanaman terung (Solanum melongena L.) dengan polietilena glikol (PEG). Jurnal Hortikultura Indonesia 6 (1): 20-28. [Indonesian]

Sobrado MA. 2007. Relationship of water transport to anatomical features in the mangrove (Laguncularia racemosa) grown under contrasting salinities. New Phytol 173: 584-591. DOI: 10.1111/j.14698137.2006.01927.x

Sokoto MB, Muhammad A. 2014. Response of rice varieties to water stress in Sokoto, Sudan Savannah, Nigeria. J Biosci Med 2: 68-74.

Swain P, Anumalla M, Prusty S, Marndi BC, Rao GJN. 2014 Characterization of some Indian native landrace rice accessions for drought tolerance at seedling stage. J Aust Crop Sci 8 (3): 324-331.

Tian WM, Yang SG, Shi MJ, Zhang SX, Wu JL. 2015. Mechanical wounding-induced laticifer differentiation in rubber tree: An indicative role of dehydration, hydrogen peroxide, and jasmonates. · J Plant Physiol 182 (15): 95-103.

Vanhove AC, Vermaelen W, Panis B, Swennen R, Carpentier SC. 2012. Screening the banana biodiversity for drought tolerance: Can an in vitro growth model and proteomics be used as a tool to discover tolerant varieties and understand homeostasis. Frontiers Plant Sci 3: 1-10. DOI: $10.3389 /$ fpls.2012.00176

Widyastuti Y, Purwoko BS, Yunus M. 2016. Identifikasi toleransi kekeringan tetua padi hibrida pada fase perkecambahan menggunakan polietilen glikol (PEG) 6000. Jurnal Agronomi Indonesia 44 (3): 235. DOI: 10.24831/jai.v44i3.13784 [Indonesian]

Xianhai Z, Feng A, Mingdao C, Junming C, Weifu L. 2010. Analysis of the principal component and the subordinate function on Rubber seedling drought resistance under hypertonic solution stresses. Chinese Trop Agric Sci 26 (1): 260-264.

Zhang C, Shangli S, Zhen L, Fan Y, Guoli Y. 2019. Drought tolerance in alfalfa (Medicago sativa L.) varieties is associated with enhanced antioxidative protection and declined lipid peroxidation. J Plant Physiol 232: 226-240. DOI: 10.1016/j.jplph.2018.10.023

Zewei A, Qitong W, Yanshi H, Yanhong Z, Yacao L, Han C, Huasun H. 2012. Co-extraction of high-quality RNA and DNA from rubber tree (Hevea brasiliensis). Afr J Biotechnol 11 (39): 9308-9314.

Zuyasna E, Chairunnas, Arwin. 2016. Efektivitas polietilen glikol sebagai bahan penyeleksi kedelai kipas merah bireun yang diradiasi sinar gamma untuk toleransi terhadap cekaman kekeringan. J Floratek 11 (1): 66-74. [Indonesian] 